Indexed by

\title{
INVESTIGATION OF THE LOSSES OF PHOTOVOLTAIC
SOLAR SYSTEMS DURING OPERATION UNDER PARTIAL SHADING
}

Crossref

KOBSON

8.

\section{Pavel Nikolaevich Kuznetsov}

Sevastopol State University,

Nuclear Energy and Industry

Institute, Sevastopol,

Russian Federation

\section{Hayder Abdulsahib Issa}

University of Thi-Qar, College

of Arts, department of Arabic

language, Thi-Qar, Iraq
Layth Mohammed Abd Ali

University of Kufa, Presidency

University of Kufa, Najaf, Iraq

Hayder Jasim Mohammed

University of Misan, College of Engineering, Mechanical Department, Misan, Iraq

\section{Vladimir Vladislavovich Kuvshinov}

Sevastopol State University, Nuclear Energy and Industry Institute, Sevastopol, Russian Federation

\section{Ali Ghanim Al-bairmani}

Sevastopol State University, Nuclear Energy and Industry Institute, Sevastopol, Russian Federation

Key words: photoelectricity, commutation, shading, increase of efficiency, solar energy, solar arrayssolar power plant doi:10.5937/jaes18-24460

Cite article:

Kuznetsov, N. P., Abd Ali, M. L., Kuvshinov, V. V., Issa, A. H., Mohammed, J. H., \& Al-bairmani, G. A. [2020]. Investigation of the losses of photovoltaic solar systems during operation under partial shading. Journal of Applied Engineering Science, 18(3), 313 - 320.

Online aceess of full paper is available at: www.engineeringscience.rs/browse-issues 


\title{
INVESTIGATION OF THE LOSSES OF PHOTOVOLTAIC SOLAR SYSTEMS DURING OPERATION UNDER PARTIAL SHADING
}

\author{
Pavel Nikolaevich Kuznetsov', Layth Mohammed Abd Ali2*, Vladimir Vladislavovich Kuvshinov', \\ Hayder Abdulsahib Issa ${ }^{3}$, Hayder Jasim Mohammed ${ }^{4}$, Ali Ghanim Al-bairmani ${ }^{1}$ \\ ${ }^{1}$ Sevastopol State University, Nuclear Energy and Industry Institute, Sevastopol, Russian Federation \\ ${ }^{2}$ University of Kufa, Presidency University of Kufa, Najaf, Iraq \\ ${ }^{3}$ University of Thi-Qar, College of Arts, department of Arabic language, Thi-Qar, Iraq \\ ${ }^{4}$ University of Misan, College of Engineering, Mechanical Department, Misan, Iraq
}

The article deals with research in solar power plants and Renewable Energy Laboratory. The purpose of research was to study the influencing of partial shading on the energy efficiency of photovoltaic installations in various connection options. As the title implies the article describes a study of the possibilities of increasing their energy efficiency when operating under different conditions. It is spoken in detail about replacement of "block connection" panels to the "in-line connection", in case of partial shading by the previous string. It is shown that substitution allows to obtain a significantly higher power - up to 8 times. It is examined that the horizontal arrangement of the panels instead of the vertical, under the same conditions, also allows up to 5 times the power of the partially shaded array in the case "in-line connection" and by $34 \%$ in the case of a "block connection". It is analyzed that parallel connection of partially shaded photovoltaic array with normally illuminated, requires voltage matching, for the selection of electrical energy at the point of maximum power, which makes it possible to obtain much more energy from the shaded array. It is experimentally shown that when using the "Intelligent maximum power selection device" that implements the voltage matching, it is possible to increase the array power up to 4 times with partial shading of 3 panels of 18 . It should be noted that the choice of methods that allow receiving energy from shaded panels through individual matching converters does not permit significantly increasing the energy production of partially shaded array. It is experimentally shown that as a result of their use the array power does not increase by more than $2.5 \%$. The results of research can be used in the design of new installations based on photovoltaic cells and the modernization of existing ones.

Key words: photoelectricity, commutation, shading, increase of efficiency, solar energy, solar arrayssolar power plant

\section{INTRODUCTION}

Global development of power plants operating from renewable energy sources shows that one of the most dynamically developing areas of this energy sector is solar photovoltaics. For the last 10 years the annual growth of electricity generation due to this resource has reached up to $20-30 \%$ with the expected level of $6.2 \%$ in global electricity production. The advantages of this energy source are environmental friendliness, which makes it possible to use it at almost any scale without bringing harm to the environment, as well as "availability at almost every place on our planet with the difference in radiation density by no more than twice" [1]. In addition, the modular design of photovoltaic plants allows them to be designed for almost any power limit, which makes these plants a multi-purpose and reliable solution, which is widely, used both in industrial production of electricity and in small energy supply systems.

It often happens that in the process of designing solar installations, design options for placing photovoltaic panels are used, assuming their operation in conditions of uneven lighting, or partial shading over a sufficiently long period of time (see Figure 1) [2,3]. The use of such schemes is connected with limited area of the installation to be designed, necessity to save space or landscape features. Moreover, studies conducted by the authors at existing solar power plants and installations at the city of Sevastopol, the Republic of Crimea, show that such design does not often take into account some features of the operation of photovoltaic (PV) solar systems, which results in a significant reduction in their efficiency, which is already low [4].

In addition, uneven illumination of solar cells can occur due to factors which do not dependent on the design. For example - a shadow of a building standing nearby, a power transmission tower, trees (see Figure $1 \mathrm{e}$ ) and others.

The purpose of our research is to increase the energy efficiency of photovoltaic installations operating in conditions of uneven illumination or partial shadowing of PVsolar systems using various connection options and methods for selecting electric energy [5].

To achieve this goal, the following tasks have been solved:

- studying the effect of uneven lighting or partial shading on the energy efficiency of photovoltaic installations with various connection options;

- determining the most favorable option for connection 


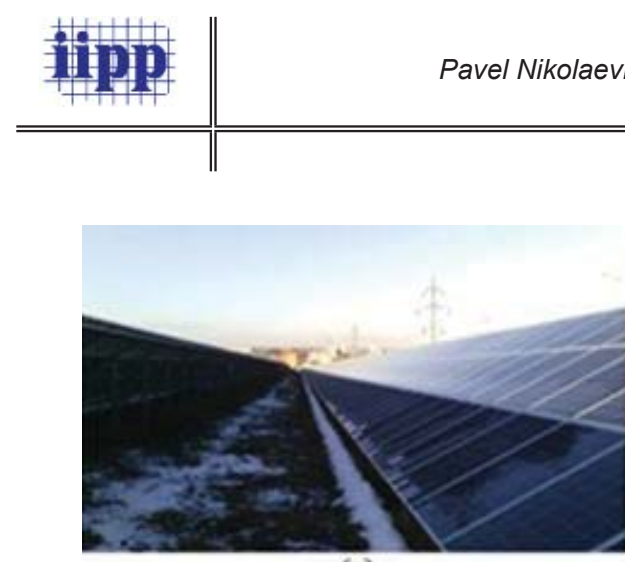

(a)

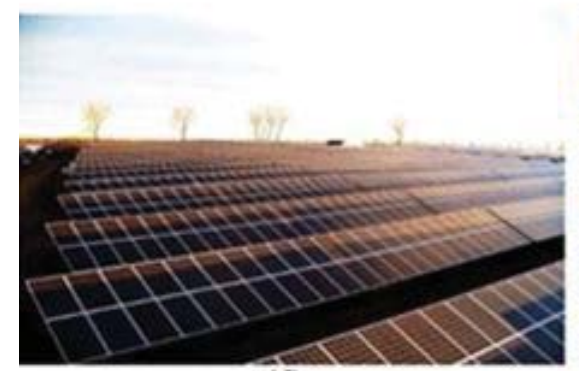

(d)

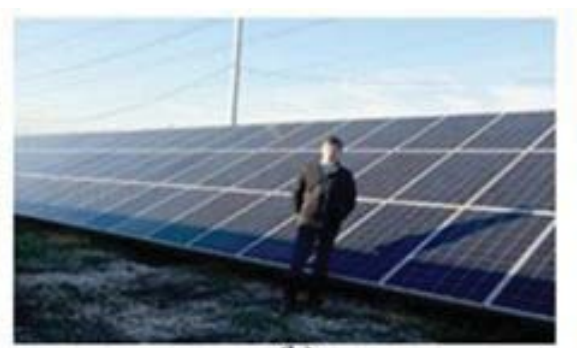

(b)

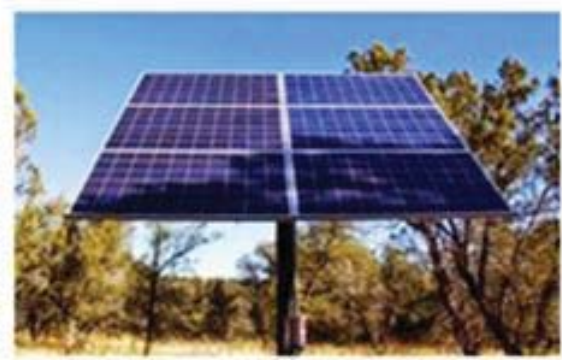

(e)

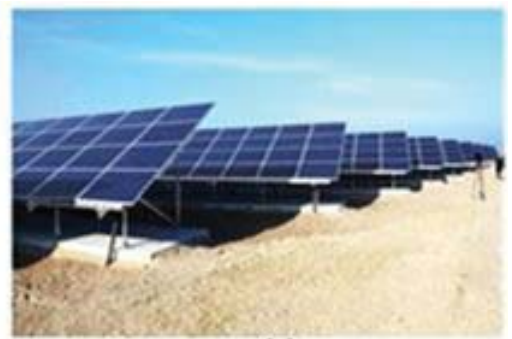

(c)

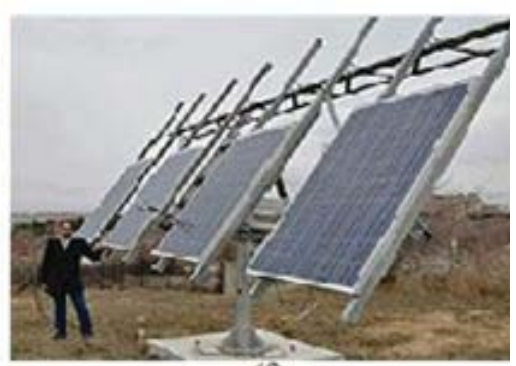

(f)

Figure 1: Photovoltaic power plants and installations operating in conditions of uneven lighting

- and the method of selection of electric energy from photovoltaic installations operating in conditions of uneven lighting or shading [6].

\section{CONDITIONS, MATERIALS AND METHODS}

The studies were carried out at existing solar power plants and installations in Sevastopol (LLC "S. Energy-Sevastopol") with an installed capacity of $2.99 \mathrm{MW}$, Republic of Crimea (LLC "RPC Energospets proekt") and also carried out in the laboratory of Renewable energy sources of Sevastopol State University with an installed capacity of $10 \mathrm{~kW}$.

The objects of the study were commercially available photovoltaic panels: PS-250, KV-260, KV-245, RZMP220 , array composed of them with various connection options, reversible converters with built-in search function for the maximum power point - Fronius Agillo Outdoor 100.0-3, Santerno Sunway TG 600V, as well as devices that carry out various methods of selecting electric energy from solar cells with partial shading, are individual matching Max Maxizer converters from Tigo Energy, USA and the "Intelligent Maximum Power Take-Off Device with harmonizing of $\mathrm{PV}$ array "made at the expense of means, received through the grant Innovation assistance Fund [7].

The calculation of the intensity of solar radiation was carried out using the method of "light equivalent" on the basis of the measured illumination with HS1010A and Yu116 luxmeters. Electrical characteristics were measured with APPA-99III and UNI-TUT33C multimeters, as well as with built-in indication of inverters [8].

The experiment was carried out in 5 stages, during which the current-voltage and power characteristics of the photovoltaic array were obtained, consisting of 18-typho-electric panels connected in series for the following conditions:
1. Even illumination of all the panels in the array [9].

2. Partial shading of a group of photovoltatic plates (the shading area was $10 \%$ of the area of shaded group panels) which consisted of lower row panels at different connection options - block vertical" and "horizontal", "in-line vertical" and "horizontal" as shown as in fig. 2.

3. Parallel connection of a photovoltaic array having a group of partially shaded photovoltaic panels (as in the $2^{\text {nd }}$ stage of the experiment) with evenly lit arrays and the installed Intelligent device for selecting maximum power and matching photovoltaic arrays as shown as in fig. 2

4. Partial shading of the group of photovoltaic panels having a group of partially shaded photovoltaic panels (as at the $2^{\text {nd }}$ stage of the experiment) with evenly lit arrays and Intelligent Maximum Power selecting and PV arrays harmonizing Device installed

5. Partial shading of a group of photovoltaic panels (as at the $2^{\text {nd }}$ stage of the experiment) with individual matching converters installed on each shaded panel when connected in parallel with evenly lit arrays [10-12].

During the experiment, RSPPS-3-19 and RZV-31B rheostats were used as a load, in series with which an ammeter was turned on (APPA 503 multimeter, included in the SI State Register under number 49266-12 until 02.17.22, with an error of DC measurements: $(0.2 \%+40$ count units) in the range from $40 \mathrm{~mA}$ to $10 \mathrm{~A}$ ). The voltage was measured directly on the terminals of the rheostats by means of a UNI-T UT39B multimeter having an error of $\pm(0.5 \%+1$ counting units $)$ in the range from $200 \mathrm{mV}$ to $1000 \mathrm{~V}$.

The intensity of solar radiation was $700 \mathrm{~W} / \mathrm{m}^{2}$, in the shade $-100 \mathrm{~W} / \mathrm{m}^{2}$ [13]. 


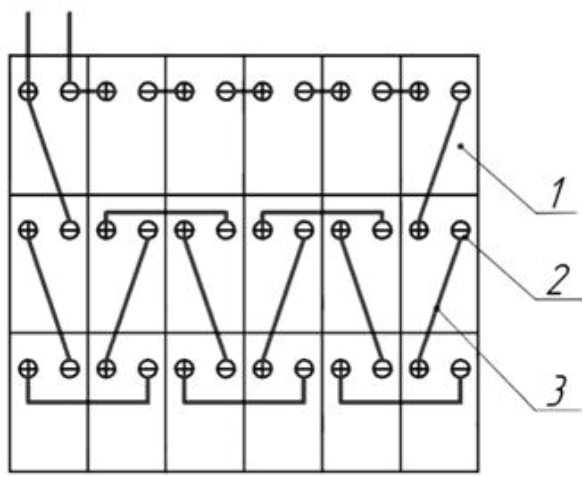

a)

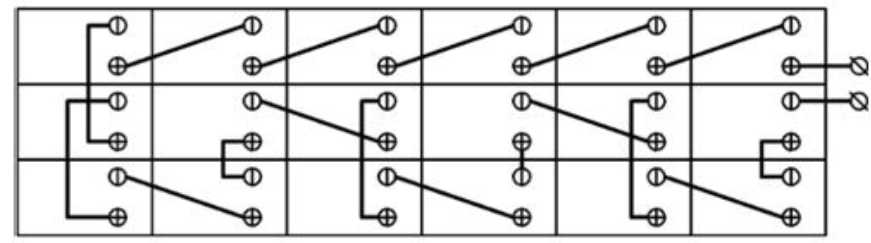

c)

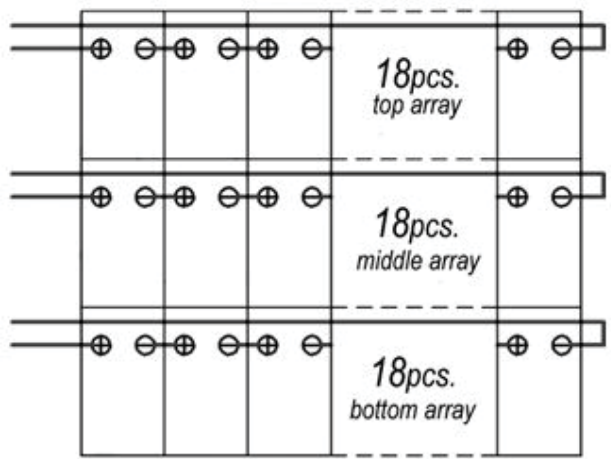

b)

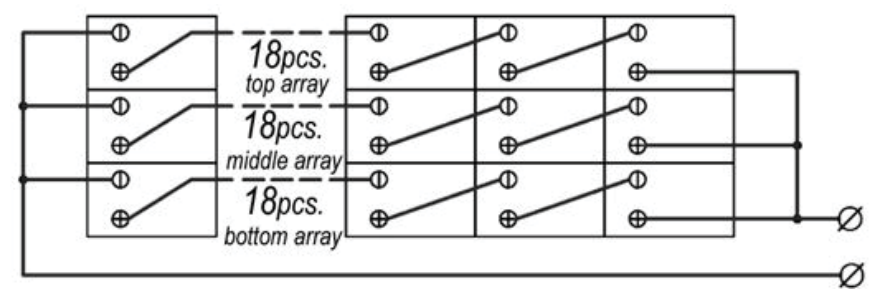

d)

Figure 2: Options for connection photovoltaic panels into the array

1 - photovoltaic panel, 2 - terminals, 3 - connecting wires (a - block vertical, b - in-line vertical, c - block horizontal, $d$ - in-line horizontal)

A functional diagram of the measuring installation and a photo illustrating the process of connecting the measuring devices and the load in the connecting panel of the solar power station and the testing ground of the laboratory of Renewable energy sources at Sevastopol State University are shown in Figure 3 [14].

During the first stage of the experiment, the photovoltaic panels of the array were evenly illuminated, as a result of which the current I flowing through all photovoltaic cells was the same and the voltage of the array $U$ was equal to the sum of the voltages of each photovoltaic array. The current-voltage characteristic of the array in the

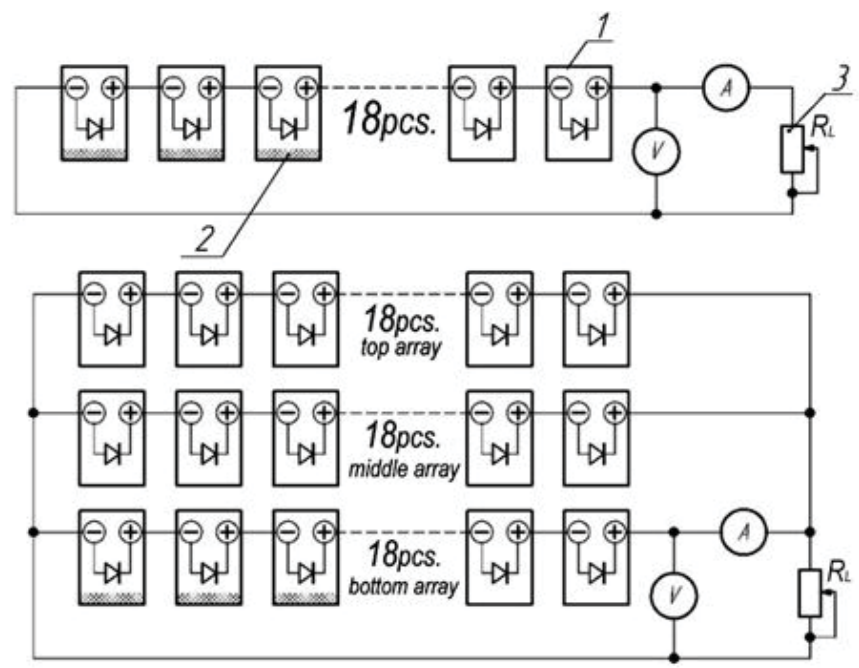

Figure 3: Functional diagram of the experimental installation

1 - photovoltaic panel, 2 - shadow, 3 - load first quadrant (photogalvanic mode) is described by the Shockley equation, with the assumption that the shunt resistance of the PV solar system is in significant:

$$
\left\{\begin{array}{l}
I=I_{p h}-I_{0}\left[\exp \left(\frac{q\left(U+I R_{s}\right.}{\mathrm{AkT}}\right)-1\right] \\
I_{\phi}=\left[I_{s c(s t c)}+K_{i}\left(T-T_{s t c}\right)\right] \frac{\beta}{\beta_{s t c}} \\
T=T_{a t}+K_{t} \beta, \\
I_{0}=\frac{I_{\phi}}{\exp \left[\frac{q\left[U_{o c}+K_{u}\left(T-T_{s t c}\right)\right]}{A k T}\right]-1}
\end{array}\right.
$$

where $I$ - load current, (A); $I_{p h}$ - photocurrent, (A); $I_{d}$ - the current flowing through the diode, $(A) ; I_{0}$ - reverse saturation current, $(\mathrm{A}) ; \boldsymbol{q}$ - is the electron charge, (1.602 • $\left.10^{-19} \mathrm{C}\right) ; U$ - output voltage, $(\mathrm{V}) ; k$ - the Boltzmann constant, $(1.381 \cdot 10-23 \mathrm{~J} / \mathrm{K}) ; T$ - the absolute temperature of the solar cell, $(\mathrm{K}) ; R_{s}$ - series resistance of the solar cell, (Ohm); $A$ - coefficient of ideality, depending on the thickness of the $p$-n-junction and the material, takes values for silicon PEC from 1.2 to $5 ; I_{s c(s t c)}$ - the SC current in standard test conditions (STC); $K_{u}$ - temperature coefficient of no-load voltage, (V/K); $T_{a t}-$ ambient temperature, $(\mathrm{K}) ; U_{o c}$ - open circuit voltage, $(\mathrm{V}) . K_{t}$ - temperature coefficient of temperature increase, $\left(\left(\mathrm{K} \cdot \mathrm{m}^{2}\right) / \mathrm{W}\right) ; \beta$ - intensity of solar radiation, $\left(\mathrm{W} / \mathrm{m}^{2}\right) ; \beta_{\text {stc }}$ - intensity of solar radiation at stc, $\left(\mathrm{W} / \mathrm{m}^{2}\right)$.

When a partial shadowing of the array occurred (stage 2 of the experiment), it was followed by disconnection (bridging) of a group of solar cells with shading by by- 
pass diodes installed in each photovoltaic panel (three parallel pairs per panel). At the same time, the decrease in the generated power of the array occurred in different ways - depending on the option of panelsconnection. This is connected with the fact that by-pass diodes are turned on so that the panel is divided into three separate series-connected PV groups see Figure 4.

Thus, at partial shading of one of the groups, only the group with shading was disconnected, while the rest continued to work. The starting of the shaded group will occur when the current flowing through all the PVdecreases to the value at which the shaded panels will be able to generate it.

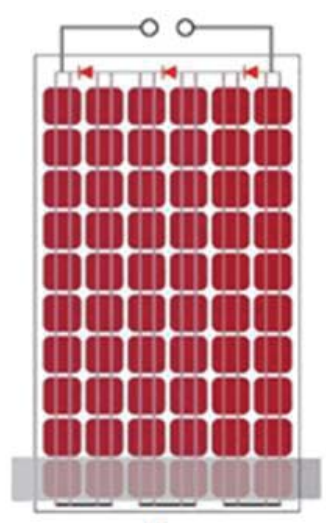

$a$

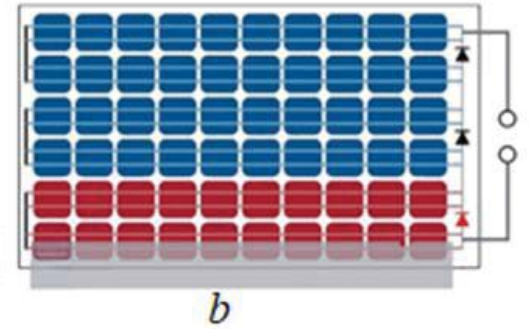

Figure 4: Disconnection of photovoltaic panel groups by by-pass diodes

(a - for block connection, b - for in-line connection)

In this case, the characteristic of the array will be formed by several characteristics - normally illuminated PV groups and groups with partial shading. Thus, the current-voltage characteristic is described by the following system of equations: where: $m$ - number of groups, having elements with different lighting; $n_{1}, n_{2}, \ldots, n_{m}$ - number of photo electric cells in a relevant group; $I_{\max 1}, I_{\max 2}, \ldots, I_{\max }-$ peak current in a relevant group, $(\mathrm{A}) ; I_{p h 1}, I_{p h 2}, \ldots, I_{p h m}-$ photogenerated current of a group at a relevant at a relevant value of solar radiation $\beta_{1}, \beta_{2}, \ldots, \beta_{m},(\mathrm{~A}) ; U_{D}-$ voltage drop across the shunt diode.

The experimental characteristics of photovoltaic arrays with different connection, with partial shading, are shown in Figure 5 (solid line):

The dependences obtained show that the decrease in the power of photovoltaic arrays, with their partial shading, occurred differently depending on the connection option between the panels. The graphs show that in this case the decrease in power was seven-fold. However, when choosing a connection option, you should not be limited to using the results obtained. Other factors must also be taken into account - the number of simultaneously working arrays without shading; the use of supplementary wires, leading to further losses and an increase in the cost of the installation as a whole; the area in which the installation is set up; inverter technical parameters.

Thus, comparing the characteristics of the array with inline vertical and block vertical connection (curve 3 and 2 in Figure 5), it is necessary to take into account the fact that in the case of in-line vertical connection, the arrays located above the partially shaded array under the study are not exposed to shading, while in the case of block connection, all arrays operate under partial shading.

Moreover, the input voltage range of the inverter can be beyond the voltage range near the peak power value, as a result of which the energy will be selected in a non-optimal mode. For example, a decrease in the energy production at Sevastopol Solar Power Plant, where the rearranging of panels connection from vertical to in-line allowed to increase the daily energy production of the station by more than twice in winter. A similar situation

$$
\left\{\begin{array}{l}
U_{1}(I)=\sum_{i=1}^{n_{1}} U_{i}(I)-U_{d} p= \\
=\frac{n_{1}(A k T)}{q} \ln \left(\frac{I_{p h 1}}{I_{0}}-\frac{I}{I_{0}}+1\right)-n_{1} I R_{s}-U_{D}\left(\frac{n_{m}-n_{1}}{Z}\right), \text { at } I>I_{\max 2} \\
U_{2}(I)=\sum_{i=1}^{n_{2}} U_{i}(I)-U_{\text {д }} p= \\
=\frac{n_{2}(A k T)}{q} \ln \left(\frac{I_{p h 2}}{I_{0}}-\frac{I}{I_{0}}+1\right)-n_{2} I R_{s}-U_{D}\left(\frac{n_{m}-n_{2}}{Z}\right), \text { at } I_{\max 2} \geq I>I_{\max 3} \\
U_{m}(I)=\sum_{i=1}^{n_{m}} U_{i}(I)=\frac{n_{m}(A k T)}{q} \ln \left(\frac{I_{p h m}}{I_{0}}-\frac{I}{I_{0}}+1\right)-n_{m} I R_{s}, \text { at } I \leq I_{\max m}
\end{array}\right.
$$



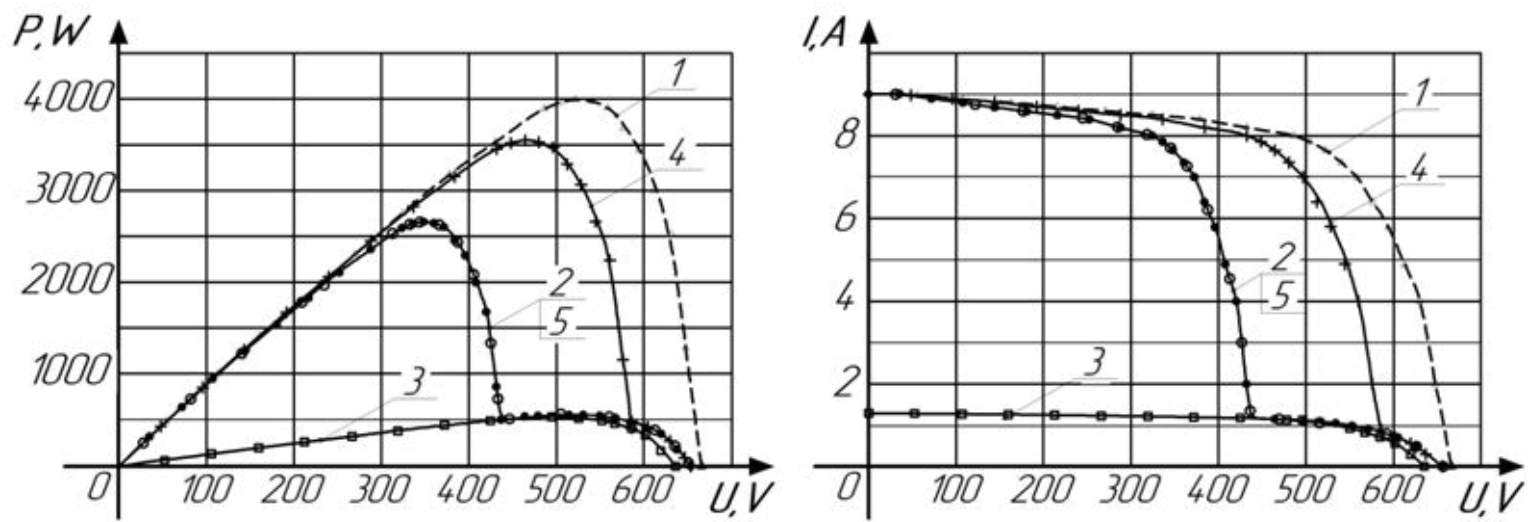

Figure 5: - Experimental characteristics of photoelectric arrays

1 - without shading, 2 - with partial shading and block vertical connection,

3 - with partial shading and in-line vertical connection and, 4- with partial shading and block horizontal connection, 5- with partial shading and in-line horizontal connection

occurred when comparing partially shaded arrays with block horizontal and in-line horizontal connection (curve 4 and 5 in Figure 5) - the decrease in power of the array with in-line connection is greater than the array with block connection, but at the same time the decrease in power of the entire power plant is less.

However, the stage of the experiment does not fully reflect the operation of the photovoltaic arrays under partial shading. This is due to the fact that the measurements were made on separate arrays that were disconnected from other parallel connected arrays. In parallel connection of arrays, electric energy is taken at a voltage corresponding to the voltage of the peak power point of the entire group of parallel connectedarrays in the input circuit of one inverter.

At the same time, the voltage at the output of partially shaded arrays and normally lit are different, since they have different points of peak power which do not match in the voltage. As a result of this, energy selection cannot be carried out in the optimal mode. To confirm this phenomenon, the $3^{\text {rd }}$ stage of the experiment was carried out.
Figure 6 shows the experimental characteristics of 2 parallel-connected photovoltaic arrays - partially shaded (with block vertical connection of panels) and normally lit (with in-line vertical connection of panels).

It can be seen from the characteristics that the peak power of parallel-connected PV arrays is less than the sum of the peak powers of individual arrays (i.e., P3max $<(\mathrm{P} 1 \mathrm{max}+\mathrm{P} 2 \mathrm{max})$ due to their voltage mismatch. Obviously, the value of the power reduction depends on the number of partially shaded panels. To study this phenomenon, an experiment was conducted in which a PV groups in a photovoltaic array were exposed to gradual partial shading - per one by-pass diode (i.e., 1/3 of the photovoltaic panel).

The array under the study was connected in parallel with twenty other uniformly lit photoelectric arrays into the input circuit of the FroniusAgilo Outdoor 100.0-3 inverter, which has a built-in search function for the peak power point. The experimental results are presented in Figure 6 (curve 1):

It can be seen from the characteristics obtained that
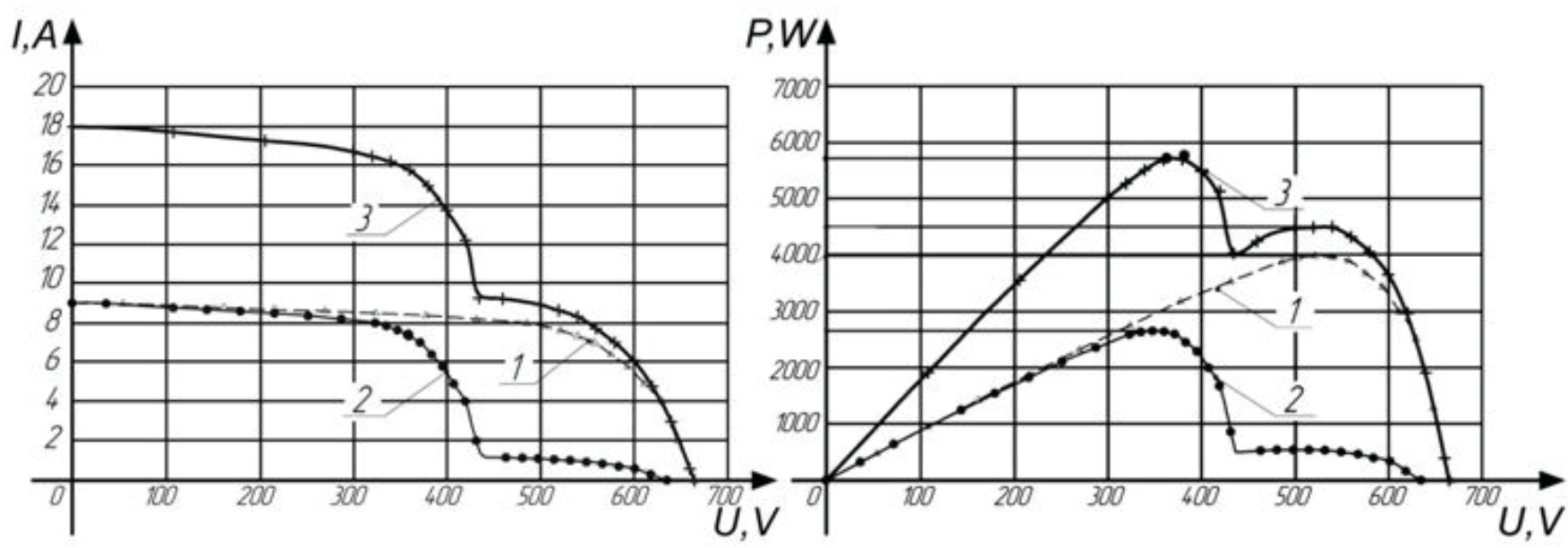

Figure 6: Experimental characteristics of two parallel-connected photoelectric arrays 1 - Array without shading, 2 - partially shaded array, 3 - parallel array connection 
even with partial shading of 2 panels, the array power decreases not by $11 \%$, but by almost $25 \%$, and when shading of 3 or more - by 5-8 times, instead of $17 \%$. The power loss value can be calculated by solving the following system of equations: generated, but only a small part of it, determined by the level of mismatch, which significantly improves the mass and size characteristics of the device (up to 18 times, in comparison with the equipment currently used), and also allows to increase efficiency and reduce cost. For prac-

$$
\begin{aligned}
& P_{\text {loss }}=U_{1 \max } n_{p} I_{1 \max }-U_{2 \max }^{\prime}\left(n_{p i l} I_{1}^{\prime}+n_{p s h} I_{2}^{\prime}\right) \\
& I_{1 \max }=I_{p h}-I_{0}\left[\exp \left(\frac{q\left(U_{1 \max }+I_{1 \max } R_{s}\right)}{n_{s i l}(\mathrm{AkT})}\right)-1\right] \text {, } \\
& I_{p h}\left(n_{p s h}+n_{p i l}\right)-\frac{U_{2 \max }^{\prime} q I_{0}}{\mathrm{~A} k T} \times \text {, } \\
& \times\left(\frac{n_{p s h} \exp \left(\frac{q\left(U_{2 \max }^{\prime}+I_{2}^{\prime} R_{s}+U_{D}\right)}{n_{s s h}(A k T)}\right)}{n_{s s h}}+\frac{n_{p i l} \exp \left(\frac{q\left(U_{2 \max }^{\prime}+I_{1}^{\prime} R_{s}\right)}{n_{s}(\mathrm{AkT})}\right)}{n_{s}}\right)=0 \text {, for } U_{2}^{\prime}<U_{2 \max }, \\
& U_{2 \max }^{\prime}=U_{1 \max }, \text { for } U_{2}^{\prime} \geq U_{2 \max }, \\
& \frac{q\left(U_{1 \max }+I_{1 \max } R_{s}\right)}{n_{s}(\mathrm{~A} k T)}-\ln \frac{I_{0}+I_{p h}}{I_{0}\left(1+\frac{q\left(U_{1 \max }+I_{1 \max } R_{s}\right)}{n_{s}(\mathrm{~A} k T)}\right)}=0, \\
& I_{1}^{\prime}=I_{p h}-I_{0} \exp \left(\frac{q\left(U_{2 \max }^{\prime}+I_{1}^{\prime} R_{s}\right)}{n_{s i l}(\mathrm{~A} k T)}\right) \\
& I_{2}^{\prime}=n_{p s h}\left(I_{p h}-I_{0} \exp \left(\frac{q\left(U_{2 \max }^{\prime}+I_{2}^{\prime} R_{s}+U_{D}\right)}{n_{s s h}(\mathrm{~A} k T)}\right)\right) \text {, for } U_{2}^{\prime}<U_{2 \max } \text {, } \\
& I_{2}^{\prime}=n_{p \operatorname{sh}}\left(I_{p h}^{\prime}-I_{0}^{\prime} \exp \left(\frac{q\left(U_{2 \max }^{\prime}+I_{2}^{\prime} R_{s}+U_{D}\right)}{n_{s i l}(\mathrm{AkT})}\right)\right), \text { for } U_{2}^{\prime} \geq U_{2 \max }
\end{aligned}
$$

where: $P_{\text {loss }}$ - power loss PV solar systems, (W); $U_{1 \max }$ $U_{2 \max }$ - the values voltage in the MPP of parallel arrays without shading and with shading, (V); $I_{1 \max }, I_{2 \max }$ - values of currents in MPP without shading and with shading, (A) $I_{1}^{\prime}$ and $I_{2}^{\prime}$ - currents in parallel connected groups without shading and with shading under voltage $U_{2 \max }^{\prime},(A)$; $I_{p h}^{\prime}$ - photocurrent of a group of solar cells with illumination equal to the illumination in the region of partial shading, (A); $l^{\prime}$ - - the inverse saturation current of a group of solar cells with an illumination equal to the illumination in the region of partial shading, $(\mathrm{A}) ; n_{p i l}, n_{p s h}-$ number of parallel-connected arrays of normal illuminated and shaded, (pcs); $n_{\text {sil, }}, n_{\text {ssh }}$ - number of series-connected photocells in an array with normal lighting and shaded, (pcs); $n_{p}$ - number of parallel-connected arrays in PV solar system, (pcs); $n_{s}$ - number of series-connected photocells in the array, (pcs).

To solve the problem of reducing the power of the array, it is necessary to match the voltage of the PV arrays. The solution to this problem was the invention of Kuznetsov P.N. and Borisov A.A. - The method of selection of electrical energy from batteries of photocell. An important feature of this method is that for the coordination of the arrays, it is necessary to convert not all the electric energy tical implementation of the method, experimental design work has been carried out to manufacture the current model of intelligent device for selecting maximum power and matching photovoltaic arrays. The device manufactured is capable of automatically matching arrays at a mismatch voltage of up to $96 \mathrm{~V}$.

At the $4^{\text {th }}$ stage of the experiment, a study of the operation of a partially shaded array was conducted with a device designed at the Sevastopol Network Solar Power Station LLC "S. Energy-Sevastopol"and autonomous solar power station in AlushtaLLC "RPC Energospetsproekt". The device was connected in series with the studied photovoltaic array (see Figure 7a) and installed in the connection panel (see Figure 7b).

The result of the experiment, shown in Figure 8 (curve 2 ), shows a significant increase in array power due to the use of the device - when shading 3 panels, the array power increases almost 4 times.

Despite the fact that the invented "Method for the selection of electrical energy from PV batteries" solves the problem of inconsistency of photovoltaic arrays, increasing their energy efficiency, the problem remains that groups of photovoltaic cells with shading remain shunted by diodes. 


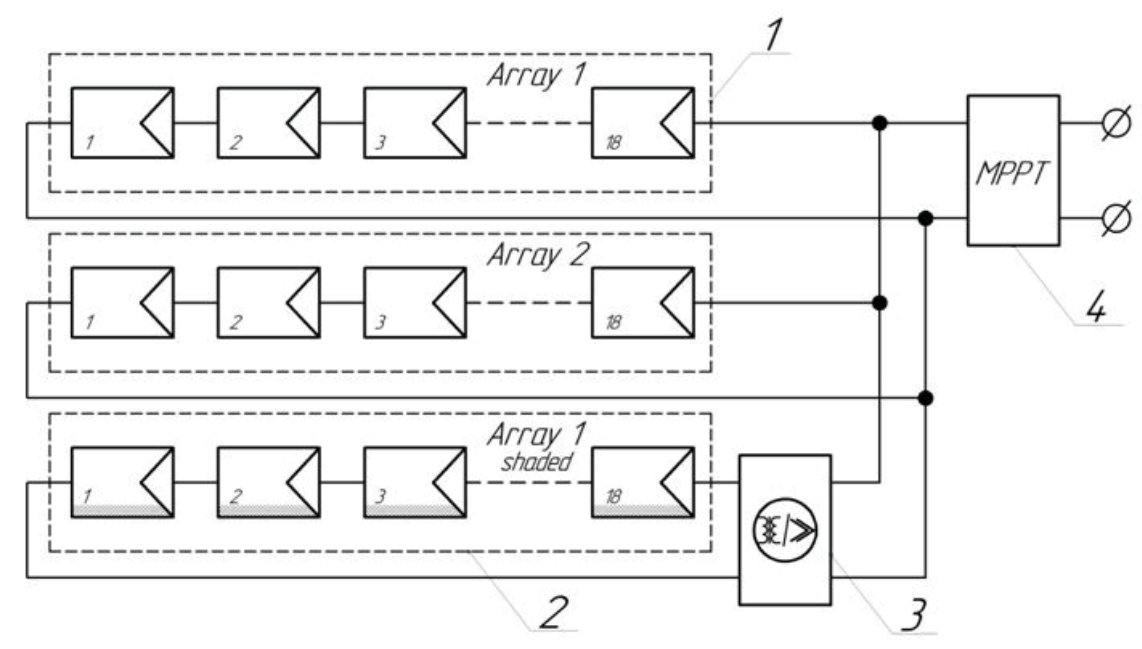

a)

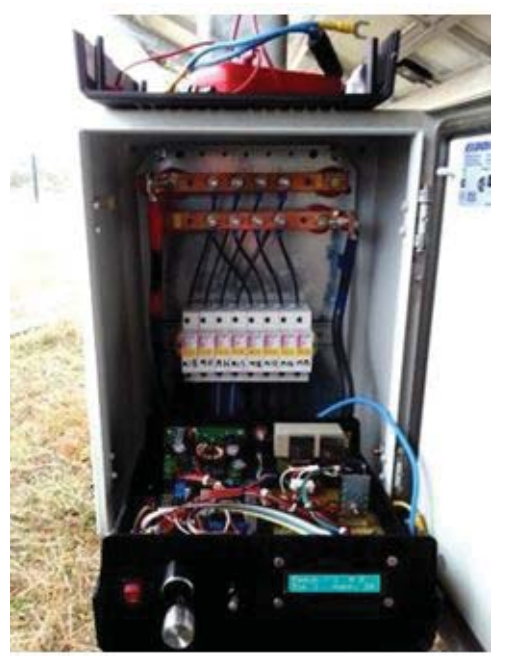

b)

Figure 7: Starting «Intelligent device for selecting maximum power and matching photovoltaic arrays» (a - structural connection scheme, $b$ - installation in the circuit breaker panel of a solar power station) 1 - evenly lit array, 2 - partially shaded array, 3 - intelligent device for selecting peak power and PV matching,

\section{4-MPPT controller}

To solve this problem, individual matching converters installed on each photovoltaic panel are used [6]. Such converters implement a method of selecting electric energy from PVC groups which generate a current, the value of which is less than in other PVC groups connected in series with it.

The principle of their operation is based on the use of DC / DCSEPIC converters with galvanic separation and an automatic control system which allows you to set the mode of electrical energy selection for a particular panel at the peak power point.

To study the operation of the photovoltaic array with individual matching converters ( $5^{\text {th }}$ stage of the experiment), «Array Maximizer» converters from Tigo Energy (USA)

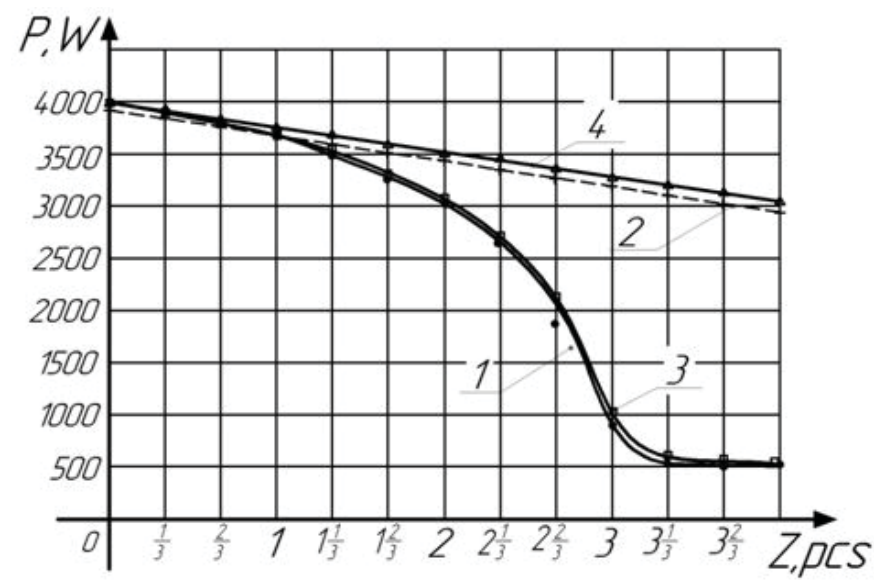

Figure 8: The graph of dependence of the photo electricarray capacity on the number of shaded panels

1 - without matching device, 2 - with matching device, 3 - with individual matching converters, 4 - with individual matching converters and a matching device were installed on shaded panels. The experimental results are shown in Figure 8 (curves 3 and 4).

The results show that the use of individual matching converters does not significantly affect the array capacity as a whole. Its maximum increase in the experiment exceeded $2.5 \%$. This is due to the fact that the output current of the panel having partial shading does not exceed the current of the shaded PV solar system, as a result of which the power generated by such a panel is not sufficient.

The results show that the use of individual matching converters does not significantly affect the array capacity as a whole. Its maximum increase in the experiment exceeded $2.5 \%$. This is due to the fact that the output current of the panel having partial shading does not exceed the current of the shaded PV solar system, as a result of which the power generated by such a panel is not sufficient.

\section{CONCLUSIONS}

Thus, the results of the study show that partial shading of photovoltaic installations significantly affects their efficiency. Moreover, the decrease in efficiency occurs in different ways depending on the option of panelsconnection. The use of in-line connection versus with block connection, is more promising from the point of view of energy efficiency, but is more expensive due to the connection of additional wires. During the design process, when choosing the vertical or horizontal orientation of photovoltaic panels, it must be taken into account that in the event of partial shading, the decrease in capacity with the horizontal arrangement of the panels will be less than with the vertical, but the area in which a power plant is located will increase. 
An interesting solution, from the point of view of increasing the energy efficiency of partially shaded photovoltaic installations, is the use of a method of selecting electric energy from batteries of photocells, implemented by theintelligent device for selecting peak power and matching photovoltaic arrays. The device allows the selection of electrical energy from the shaded array at the point of maximum power, due to its coordination in voltage with other parallel connectedarrays, which significantly increases its power generation.

\section{ACKNOWLEDGMENTS}

The authors would like to thank the Institute of Nuclear Energy and Industry in Sevastopol State University and the University of Kufa for their continuous financial and moral support. The research was carried out at the expense of the grant of Federal State Autonomous Educational Institution of Higher Education "Sevastopol State University".

\section{REFERENCES}

1. The strategy for sustainable development of rural areas of the Russian Federation for the period until 2030 dated February 2, 2015 No. 151 - $p$ // the website of the Government of Russia : http://government.ru/docs/16757/.

2. Chuikov R. Industry review and prospects for the development of solar energy in Russia // Alternative kilowatt. 2010. No2.

3. Belenov A.T. Solar Photovoltaic Water Lifts / A.T. Belenov, G.N. Brooms. - Moscow: VIESH, 2014.

4. Kuznetsov P.N., Safonov V.A. Improving the efficiency of the photovoltaic station // Energy Security and Energy Saving. 2016. No3. P. 26-30.

5. RF patent application No. 2016138181, 09/26/2016. Kuznetsov P.N., Borisov A.A. The method of selection of electrical energy from batteries of photovoltaic converters.

6. R. Faranda, S. Leva Energy comparison of MPPT techniques for PV System// Wseas transactions on power systems. June 2008; Issue 6, vol. 3: P. 446-455.
7. Kuvshinov, V.V., Kolomiychenko, V.P., Kakushkina, E.G. et al. Storage System for Solar Plants. Appl. Sol. Energy, 2019, vol. 55, no. 3, pp. 153-158. https://doi.org/10.3103/S0003701X19030046.

8. Kuvshinov, V.V., Abd Ali, L.M., Kakushina, E.G. et al. Studies of the PV Array Characteristics with Changing Array Surface Irradiance. Appl. Sol. Energy, 2019, vol. 55, no. 4, pp. 223-228 https://doi.org/10.3103/S0003701X19040054.

9. Vologdin, S.V., Yakimovich, B.A., Kuvshinov, V.V. et al. Analysis of Various Energy Supply Scenarios of Crimea with Allowance for Operating Modes of Solar Power Planta. Appl. Sol. Energy, 2019, vol. 55, no. 4, pp. 229-234. https://doi.org/10.3103/S0003701X1904008X.

10. Guryev, V.V., Yakimovich, B.A., Abd Ali, L.M. et al. Improvement of Methods for Predicting the Generation Capacity of Solar Power Plants: the Case of the Power Systems in the Republic of Crimea and City of Sevastopol. Appl. Sol. Energy, 2019, vol. 55, no. 4, pp. 242-246. DOI:10.3103/S0003701X19040042.

11. Cheboxarov, V.V., Yakimovich, B.A., Lyamina, N.V. et al. Some Results of a Study of Wave Energy Converters at Sevastopol State University. Appl. Sol. Energy, 2019, vol. 55, no. 4, pp. 256-259. DOI:10.3103/S0003701X19040029.

12. Layth Mohammed Abd Ali, Haider Ahmed Mohmmed and Husam Abdul husein Wahhab, . ANovel Design of 7-Level Diode Clamped Inverter. Journal of Engineering and Applied Sciences, 2019, no.14, pp.3666-3673. https://doi.org/10.36478/jeasci.2019.3666.3673.

13. Cheboxarov, V.V., Yakimovich, B.A., Abd Ali, L.M. et al. An Offshore Wind-Power-Based Water Desalination Complex as a Response to an Emergency in Water Supply to Northern Crimea. Appl. Sol. Energy, 2019, vol. 55, no. 4, pp. 260-264. DOI: $10.3103 / \mathrm{S} 0003701 \mathrm{X} 19040030$.

14. Abd Ali, L.M. and Issa, H.A., Hybrid power generation using solar and wind energy, Molod. Uchen., 2018, no. 7, pp. 19-26. https://moluch.ru/archive/193/48444. 